\title{
Modelamento do processo de gresificação de massas cerâmicas de revestimento
}

\section{(Modelling of the vitrification process of ceramic bodies for whiteware)}

\author{
L. Sánchez-Muñozi, S. da S. Cava', C. A. Paskocimas ${ }^{2}$, E. Cerisuelo , \\ E. Longo ${ }^{2}$, J. B. Carda ${ }^{1}$ \\ ${ }^{1}$ Dpto. Química Inorgánica y Orgánica, Universidad Jaume I, Castellón, Espanha. \\ ${ }^{2}$ Centro Multidisciplinar de Desenvolvimento de Materiais Cerâmicos, \\ Departamento de Química, UFSCar \\ C.P. 676, S. Carlos, SP, Brasil, 13560-905 \\ ${ }^{3}$ Tierra Atomizada, S.A., Alcora, Castellón, Espanha
}

\begin{abstract}
Resumo
Foi proposto um modelo para o processo de gresificação de massas cerâmicas de grés porcelânico, baseado na correlação entre a porosidade e os componentes da massa e sua evolução com a temperatura. A aplicação do modelo foi realizada empregando uma frita especialmente desenvolvida como fundente e uma composição otimizada de argila e caulim. Assim, desenvolveu-se uma massa de grés porcelânico de baixa temperatura de queima $\left(\sim 1150^{\circ} \mathrm{C}\right)$ e uma faixa de estabilidade dimensional de aproximadamente $100^{\circ} \mathrm{C}$.

Palavras-chave: curva de gresificação, grés porcelânico.
\end{abstract}

\begin{abstract}
A model was proposed for the vitrification process of ceramic bodies for porcelain stoneware tiles, based on the correlation among the porosity and the mixture components and its evolution with temperature. The application of the model was accomplished using a frit especially designed as flux and an optimized composition of clay and kaolin. Accordingly, a porcelain stoneware tile body for low firing temperature $\left(1150{ }^{\circ} \mathrm{C}\right)$ and a dimensional stability range of approximately $100^{\circ} \mathrm{C}$ has been developed.
\end{abstract}

Keywords: vitrification curve, porcelain stoneware tile.

\section{INTRODUÇÃO}

A gresificação de massas cerâmicas é a medida da evolução da microestrutura do material durante a queima. A curva de gresificação utilizada em revestimentos cerâmicos ilustra o comportamento térmico do material em função da temperatura. Normalmente, é representada por dois parâmetros: porosidade e sinterização. A porosidade pode ser medida pela absorção de água (método mais simples e mais utilizado) ou porosimetria de mercúrio, enquanto que a sinterização [1] é medida por retração linear (mais utilizado) ou expansão térmica.

Na Fig. 1 são apresentados dois exemplos de curvas de gresificação. No caso "1", o mínimo de absorção de água é coincidente com o máximo de retração linear, que corresponde à temperatura ótima de queima $T_{0}$. Também, para temperaturas superiores a $T_{0}$, os valores de retração linear e absorção de água se mantém constantes, isto é, ocorre a estabilidade dimensional. Esta característica é essencial nos revestimentos, pois implica em dimensões constantes nas peças, para as pequenas variações na temperatura de queima do forno. No caso " 2 ", estas características não ocorrem porque a temperatura do máximo de retração linear, que corresponde a uma temperatura não-ótima de queima $\mathrm{T}_{\text {no }}$ não coincide com a

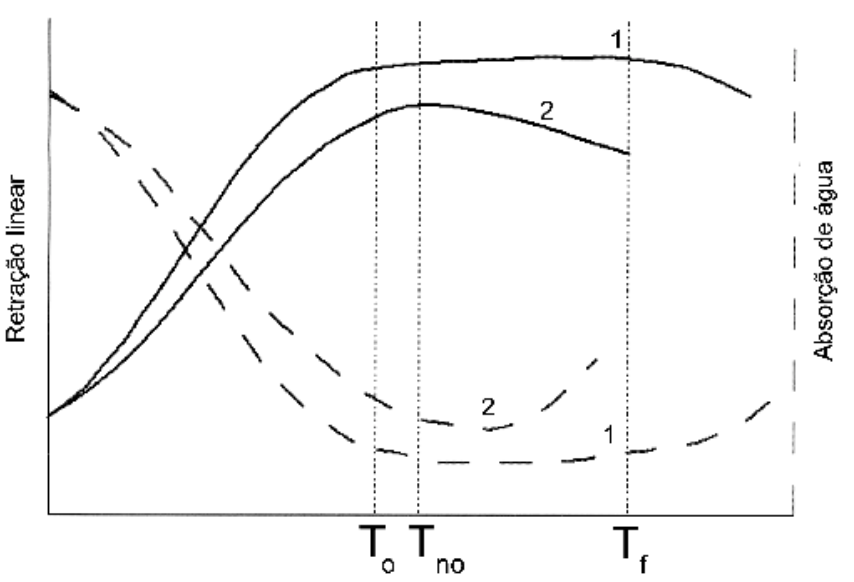

Figura 1: Dois exemplos de curvas de gresificação. As curvas 1 correspondem à massas com uma formulação otimizada em termos de matérias-primas, enquanto que as curvas 2 correspondem aos casos em que a composição em matériasprimas da massa está incorreta.

[Figure 1: Two examples of vitrification curves. Curves 1 correspond to masses with an optimized formulation in terms of raw materials, while curves 2 correspond to the cases in that the raw materials composition of the mixture is incorrect.] 
temperatura que aparece o mínimo de absorção de água. Nestes casos, é comum que os valores de absorção de água próximos de zero não sejam atingidos. A temperaturas superiores a $T_{n o}, a$ curva da retração linear cai porque ocorrem fenômenos de dilatação superior aos de retração, enquanto que os valores de absorção de água continuam diminuindo até que seja estabilizado, para depois aumentar de forma muito pronunciada.

Em relação a tudo o que foi mencionado, o objetivo geral deste trabalho é elaborar um modelo geral do processo de gresificação de massas cerâmicas, identificando as causas dos diferentes tipos de porosidade e sua relação com o comportamento de gresificação (Fig. 1). Em outras palavras, pretende-se elaborar um modelo que correlacione a evolução dos diferentes tipos de porosidade com o aumento da temperatura, e também, com cada um dos componentes das massas. Finalmente, o modelo proposto será aplicado para desenvolver novas massas cerâmicas de grés porcelânico que gresifiquem à mínima temperatura possível e com a máxima faixa de estabilidade dimensional.

\section{PROCEDIMENTOEXPERIMENTAL}

A metodologia de trabalho usada neste trabalho, conforme representa a Fig. 2, é a proposta de um modelo do processo de gresificação de massas cerâmicas, e a subseqüente aplicação do modelo, com a seleção de matérias-primas para a obtenção de massas cerâmicas muito próximas do modelo proposto.

Para a aplicação do modelo, foi desenvolvida uma massa cerâmica de queima branca. Foi utilizada uma amostra de argila (M1) de qualidade industrial. O caulim (M2) foi selecionado por ser um caulim de alto conteúdo em caulinita.

Uma frita cerâmica (M3) foi otimizada para obter uma temperatura de fusão baixa o suficiente para uma alta viscosidade de fundido [2]. Estas são as características fundamentais que deve apresentar um fundente empregado para

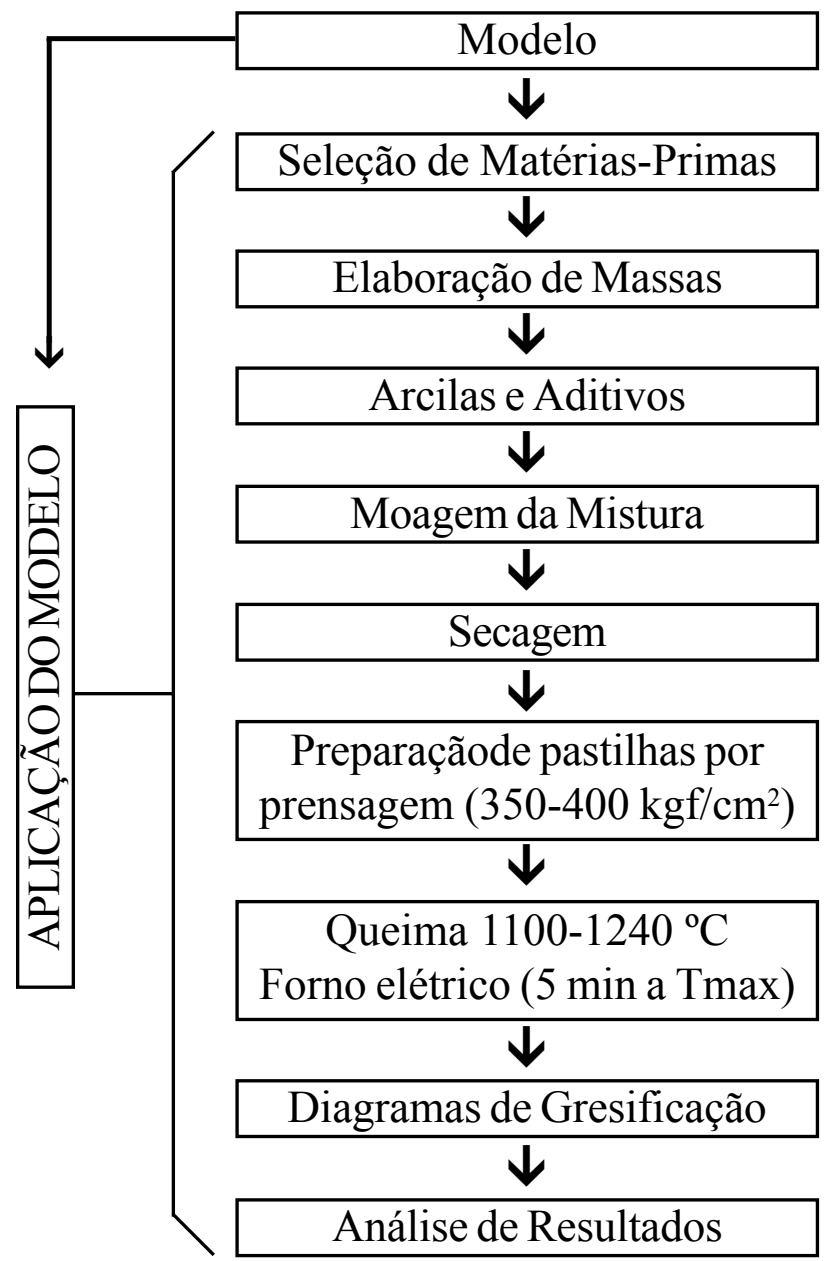

Figura 2: Esquema da metodologia de trabalho adotada.

[Figure 2: Outline of the adopted work methodology.]

Tabela I - Análises químicas das diversas matérias-primas estudadas (M1, M2 e M3).

[Table I - Chemical analysis of different used raw materials (M1, M2 and M3).]

\begin{tabular}{lllllllllll}
\hline & & $\mathrm{SiO}_{2}$ & $\mathrm{Al}_{2} \mathrm{O}_{3}$ & $\mathrm{TiO}_{2}$ & $\mathrm{Fe}_{2} \mathrm{O}_{3}$ & $\mathrm{CaO}$ & $\mathrm{MgO}$ & $\mathrm{Na}_{2} \mathrm{O}$ & $\mathrm{K}_{2} \mathrm{O}$ & $\mathrm{PF}$ \\
\hline \multirow{2}{*}{ Tradicional } & Argila M1 & 60,55 & 25,67 & 1,34 & 1,42 & 0,34 & 0,53 & 0,32 & 1,87 & 7,97 \\
\cline { 2 - 10 } & Caulim M2 & 57,73 & 39,52 & 0,17 & 0,91 & 0,03 & 0,20 & 0,00 & 1,43 & 0,00 \\
\hline Sintética & Frita M3 & 57,63 & 11,90 & 1,55 & 0,00 & 5,22 & 5,23 & 4,11 & 10,86 & 3,50 \\
\hline
\end{tabular}

Tabela II - Análises mineralógicas das matérias-primas estudadas (M1, M2 e M3).

[Table II - Mineralogical analysis of used raw materials (M1, M2 and M3).]

\begin{tabular}{lccc}
\hline & M1 & M2 & M3 \\
\hline Quartzo & 46 & 2 & - \\
\hline Caulinita & 32 & 90 & - \\
\hline Ilita & 22 & 8 & - \\
\hline
\end{tabular}

Tabela III - Desenvolvimento de uma massa cerâmica otimizada. [Table III - Development of a optimized ceramic whiteware.]

\begin{tabular}{lccc}
\hline Componentes & \multicolumn{3}{c}{ Massas (\%) } \\
\cline { 2 - 4 } & $\mathrm{a}$ & $\mathrm{b}$ & $\mathrm{c}$ \\
\hline M1 & 100 & 40 & 40 \\
\hline M2 & - & 40 & 40 \\
\hline M3 & - & 20 & 17 \\
\hline
\end{tabular}


a elaboração de suportes de revestimentos cerâmicos.

As respectivas análises químicas (obtidas por meio de fluorescência de raios X - FRX) e mineralógicas (obtidas por meio de difração de raios X - DRX) são apresentadas nas Tabelas I e II.

A Tabela III indica a seqüência do desenvolvimento realizado na formulação de massas cerâmicas.

Cada composição de massas foi homogeneizada mediante moagem por via úmida em um moinho rápido de laboratório. As barbotinas foram secas e peneiradas em uma peneira de $100 \mu \mathrm{m}$. Os corpos de prova cerâmicos foram conformados por prensagem em forma de pastilhas de $50 \mathrm{~mm}$ de diâmetro, utilizando uma prensa semi-automática de laboratório a pressões compreendidas entre 350 e $400 \mathrm{kgf} / \mathrm{cm}^{2}$. A queima foi realizada em um forno elétrico com uma curva de queima que simula o processo de queima industrial. As temperaturas máximas de queima para elaboração dos diagramas de gresificação foram compreendidas entre 1100 e $1240^{\circ} \mathrm{C}$, com tempos de patamar de $5 \mathrm{~min}$.

Os diagramas de gresificação foram elaborados a partir dos dados de retração linear e absorção de água.

\section{RESULTADOS E DISCUSSÃO}

Quando se pretende desenvolver uma massa cerâmica, partese de uma situação inicial definida pelo comportamento da argila plástica de forma isolada, isto é, sem aditivos. A Fig. 3a apresenta um caso de curva de gresificação na qual distingue-se uma temperatura a partir da qual se inicia o aumento da retração linear e a diminuição da absorção de água. Em geral, prefere-se as situações iniciais em que a altas temperaturas, as curvas têm inclinações positivas e negativas, respectivamente, mas sem chegar a um valor de absorção de água próximo de zero. Quando são adicionadas pequenas quantidades de materiais fundentes à argila base, as curvas se modificarão pouco e então este tipo de curva também corresponde às massas com formulações mal otimizadas por efeito dos fundentes, ou com compactação ou moagem deficiente.

Se a adição de fundentes e não-plásticos estiverem corretos para uma massa de grés ou grés porcelánico, o diagrama de gresificação obtido será semelhante ao da Fig. 3 b.

Neste caso, pode-se distinguir quatro regiões no diagrama de gresificação que são: I, II, III e IV separadas por três temperaturas $\mathrm{T}_{\mathrm{f}}$ (temperatura de formação de fase fundida), $\mathrm{T}_{\mathrm{o}}$ (temperatura ótima de queima) e $\mathrm{T}_{\mathrm{p}}$ (temperatura de perda da estabilidade dimensional).

Os principais processos que ocorrem em cada uma das quatro regiões dos diagramas de gresificação são propostos no modelo esquemático da Fig. 4.

$\mathrm{Na}$ região I, antes da temperatura de formação de fase fundida $\mathrm{T}_{\mathrm{f}}$, ocorrem todas as transformações das argilas, isto é, as desidratações e desidroxilações, assim como a transformação parcial da fração caulinítica em mulita. Os materiais fundentes não são afetados a estas baixas temperaturas. O resultado final é que se dispõem de uma microestrutura na qual ocorre a máxima porosidade aberta (isto é, absorção de água máxima).

$\mathrm{Na}$ região II, compreendida entre $\mathrm{T}_{\mathrm{f}}$ e $\mathrm{T}_{\mathrm{o}}$, formam-se os primeiros fundidos que são de dois tipos. Por um lado, ocorre a fusão parcial do material argiloso rico em $\mathrm{Na}$ e $\mathrm{K}$ (ilita e
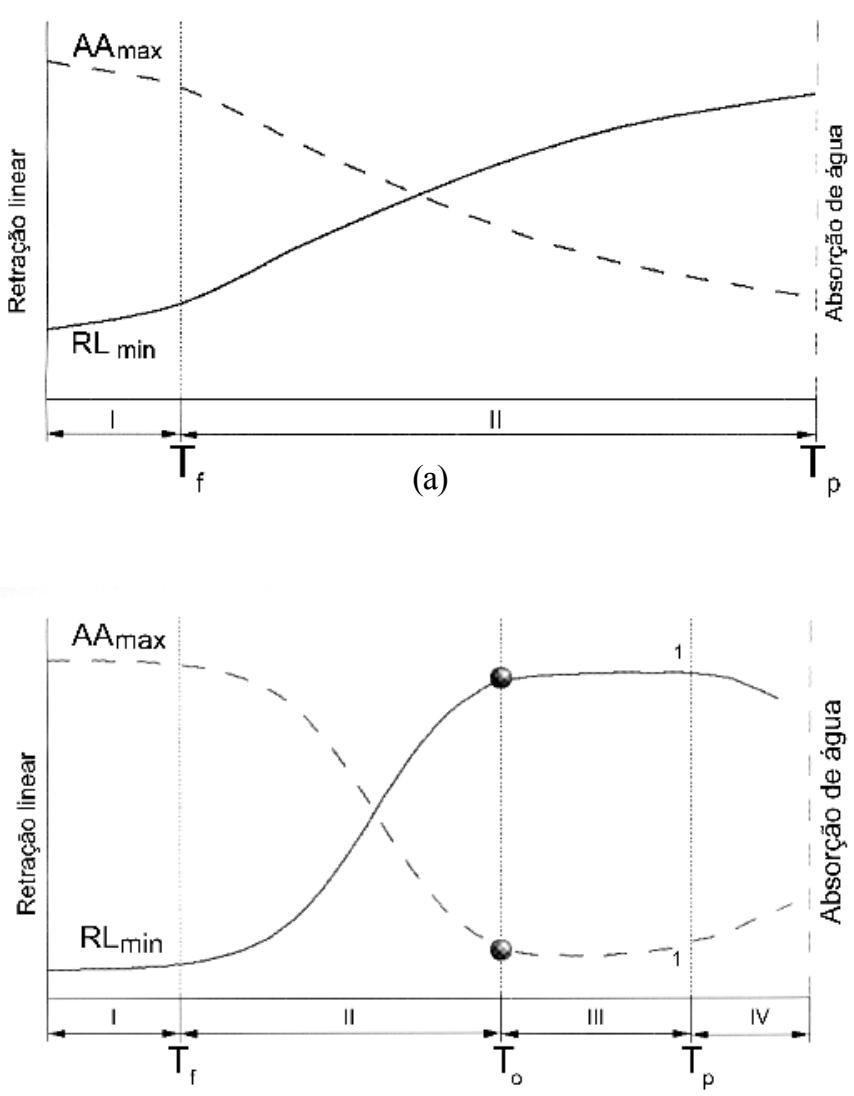

(b)

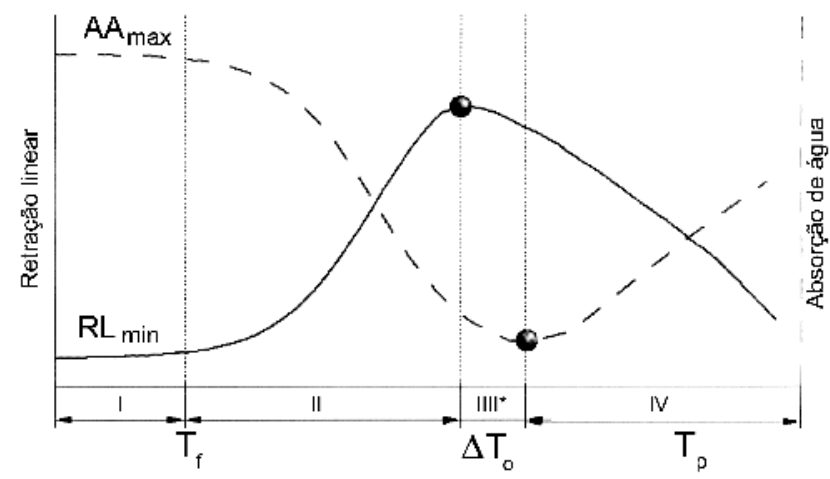

(c)

Figura 3: Desenvolvimento de curvas de gresificação. a) situação de partida da formulação (somente argila), em que não se alcança a retração linear máxima $\left(\mathrm{RL}_{\max }\right)$ e nem a absorção de água mínima $\left(\mathrm{AA}_{\min }\right)$; b) massa ideal, em que a retração linear máxima $\left(\mathrm{RL}_{\text {max }}\right)$ é atingida ao mesmo tempo em que a absorção de água mínima ( $\left.\mathrm{AA}_{\text {min }}\right)$, em uma região de estabilidade dimensional (região III); c) massa não-otimizada, em que a retração linear máxima $\left(\mathrm{RL}_{\max }\right)$ não corresponde à absorção de água mínima $\left(\mathrm{AA}_{\min }\right)$, não havendo estabilidade dimensional $\left(\Delta \mathrm{T}_{\mathrm{o}}\right)$.

[Figure 3: Development of vitrification curves. a) Starting situation of the formulation (clay only), in that neither a maximum linear shrinkage $\left(R L_{m a x}\right)$ nor a minimum water absorption $\left(A A_{\text {min }}\right)$ is reached; b) ideal mixture, in that the maximum linear shrinkage $\left(R L_{\max }\right)$ is reached at the same time that the minimum water absorption $\left(A A_{\text {min }}\right)$, in a region of dimensional stability (region III); c) non-optimized mixture, in that the maximum linear shrinkage $\left(R L_{\max }\right)$ does not correspond to the minimum water absorption $\left(A A_{\text {min }}\right)$, with no dimensional stability $\left(\Delta T_{0}\right)$.] 


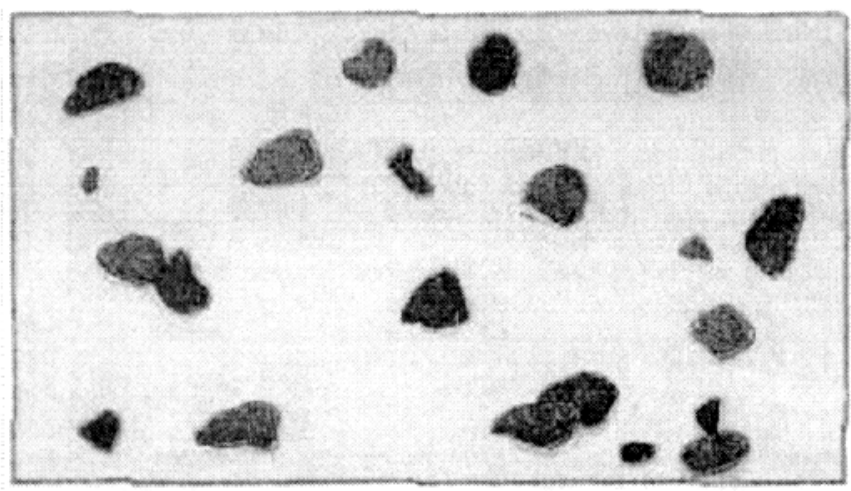

Situação de partida

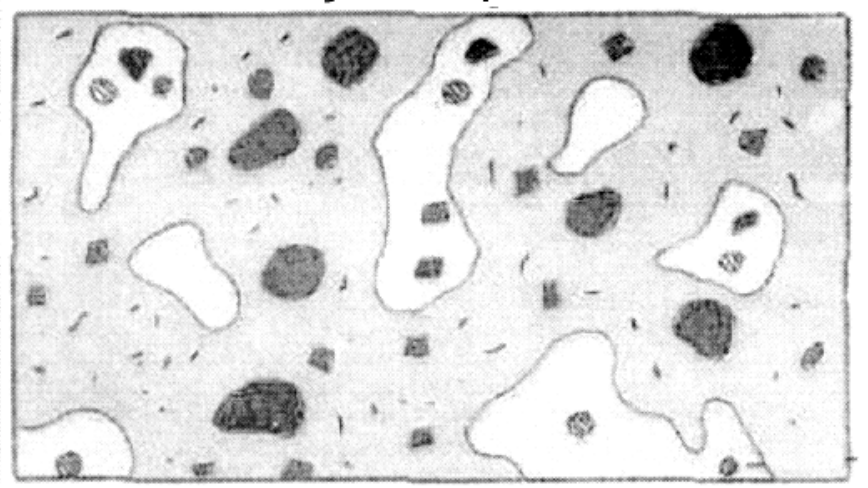

Região II

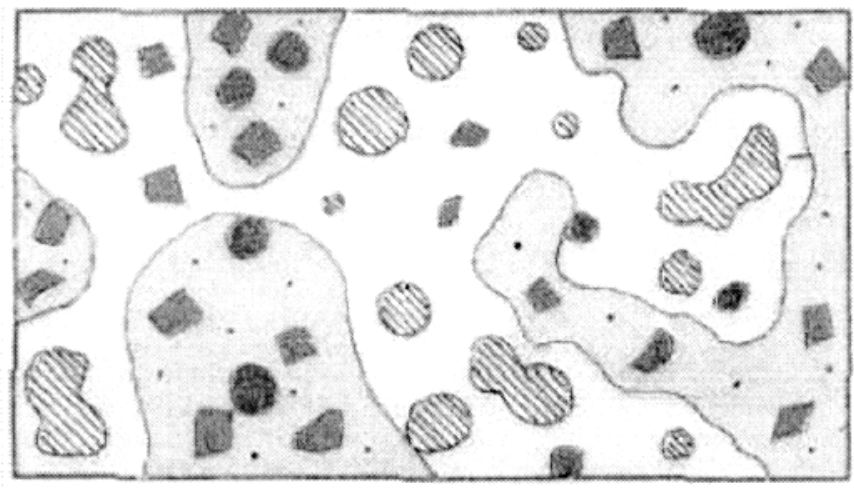

Região IV

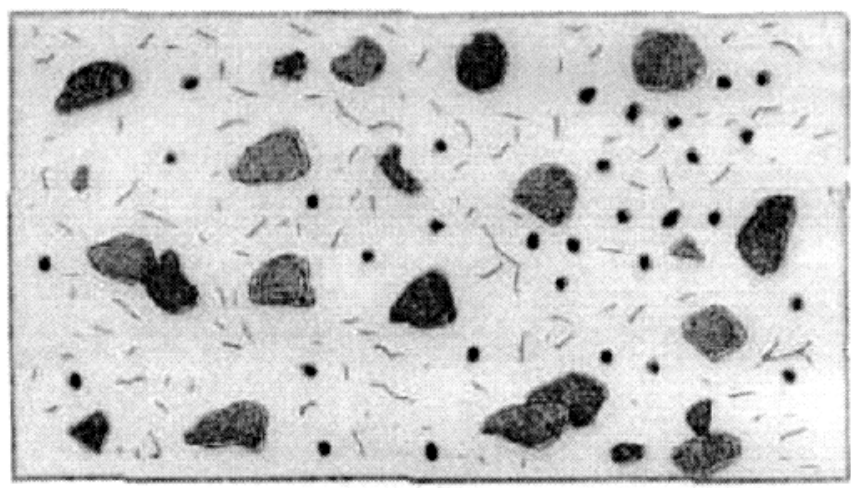

Região I

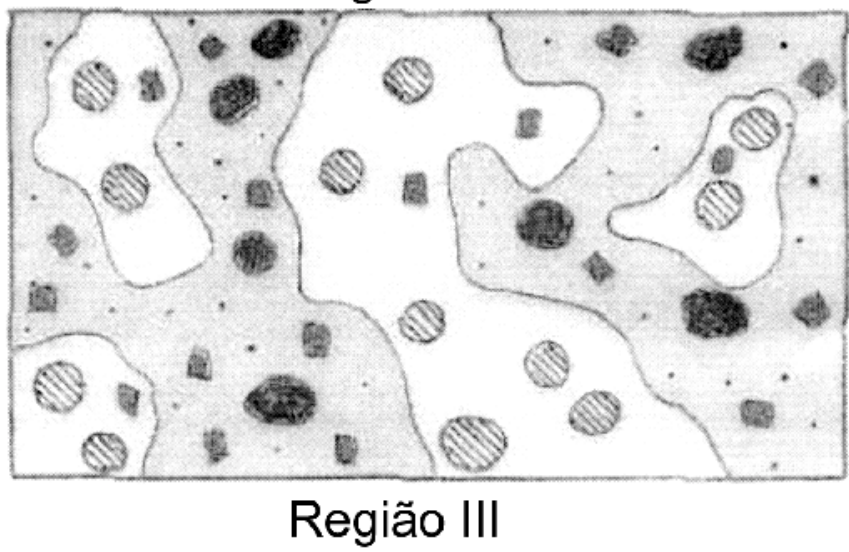

$\square$ Argila Prundente

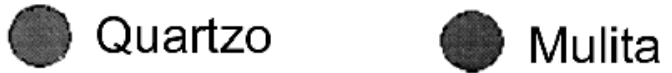

\section{S1) Porosidade aberta}

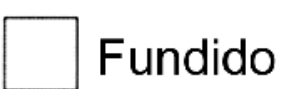

\section{QPorosidade fechada}

Figura 4: Modelo esquemático da evolução microestrutural de massas cerâmicas, desenhados conforme o comportamento de gresificação ilustrados na Fig. 3. Os detalhes são explicados no texto.

[Figure 4: Schematic model of the microstructural evolution of ceramic whitewares, drawn according to the behavior of the vitrification curve in Fig. 3. Details are explained in the text.]

montmorilonita), cuja alta viscosidade impede sua propagação. Este não desenvolve porosidade fechada porque permite o escape dos gases através da porosidade aberta. $\mathrm{O}$ fundido de alta viscosidade tende a fechar progressivamente a porosidade aberta, dando lugar à porosidade residual fechada. Por outro lado, ocorre um fundido de viscosidade mais baixa relacionado com a fusão dos fundentes que se estendem a partir destas partículas. Este pode incluir grãos de quartzo que se mantêm inalterados. É, portanto o responsável pela formação da porosidade fechada. $\mathrm{Na}$ temperatura $\mathrm{T}_{\mathrm{o}}$ ótima de queima coincide o mínimo da absorção de água e o máximo da retração linear, isto é, o processo de sinterização $[3,4]$ chega ao final.
O comportamento descrito para esta região do diagrama de gresificação termina quando se consomem todos os fundentes pelo processo de fusão. Assim, permite-se fazer a distinção entre dois tipos de queima: i) para obter um grés a $\mathrm{T}<\mathrm{T}_{\mathrm{o}}$ com existência de fundentes (normalmente feldspatos) residuais, e ii) para obter um grés porcelânico a $T \geq T_{0}$ onde todos os materiais fundentes já tornaram o fundido de baixa viscosidade.

A região III está compreendida entre $T_{o}$ e $T_{p}$, isto é, entre a queima ótima e a perda de estabilidade dimensional. Nesta região, formam-se inicialmente os poros fechados que contêm gases, produto da decomposição das inclusões ricas em elementos voláteis procedentes dos feldspatos. Com o 


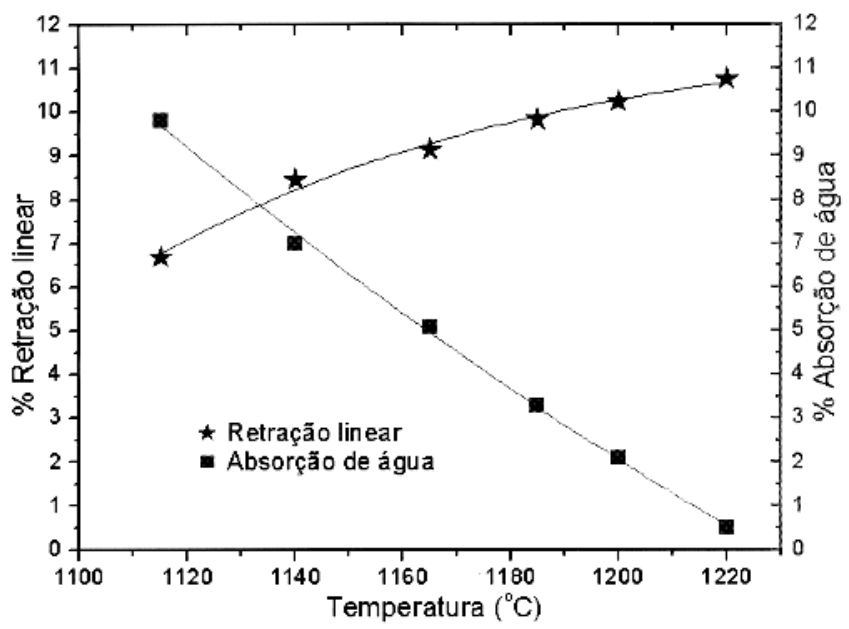

(a)

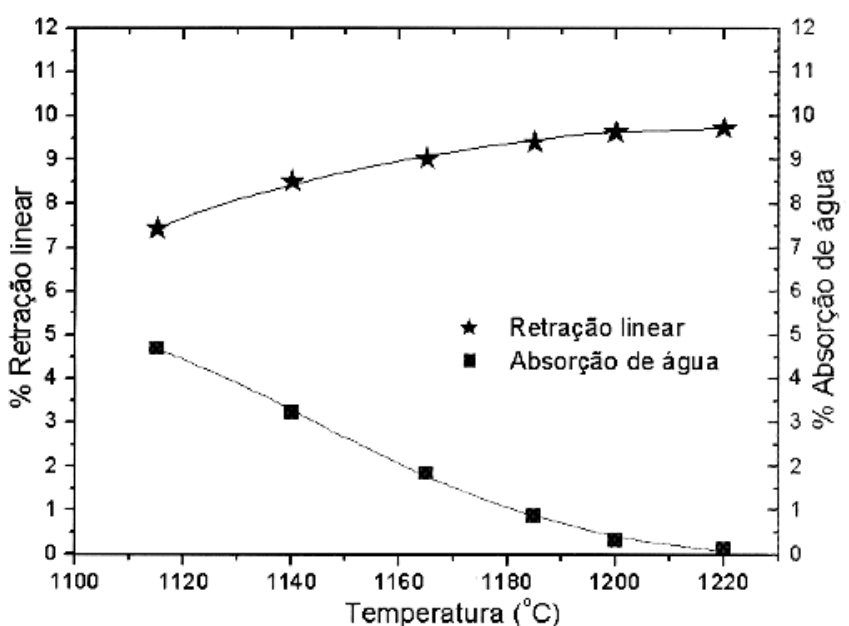

(b)

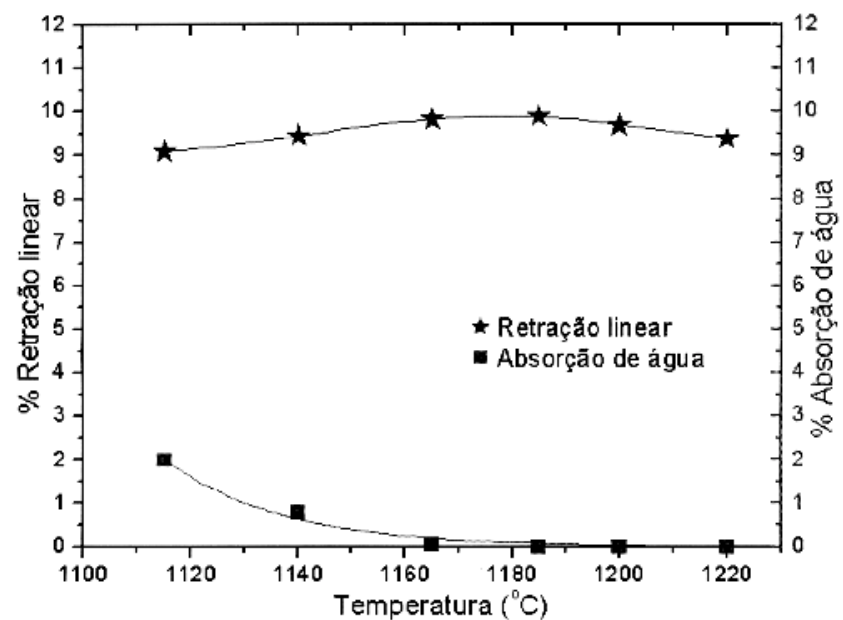

(c)

Figura 5: Aplicação do modelo, com o desenvolvimento de frita como fundente. a) massa inicial - argila M1 + caulim M2; b) adição de $10 \%$ de frita M3 à massa inicial; c) adição de 20\% de frita M3 à massa inicial.

[Figure 5: Application of the model with the development of frit as flux. a) initial mixture - clay M1 + kaolin M2; b) addition of $10 \%$ of frit M3 to the initial mixture; c) addition of $20 \%$ of frit M3 to the initial mixture.] aquecimento, os gases presos nos poros tendem a expandirse, resultando em uma força contrária à retração por densificação. Nesta região, ambos os efeitos devem ser equilibrados (se a formulação está correta) para manter a retração linear próxima a um valor constante, isto é, para proporcionar a estabilidade dimensional. Mesmo assim, o volume de fundido de baixa viscosidade continua aumentando conforme a temperatura aumenta. Quando a viscosidade do fundido é suficientemente baixa, seja por efeito da temperatura ou por sua composição química, e/ou sua proporção é muito alta pode ocorrer a deformação piroplástica da peça $a T_{p}$.

Na região IV, ocorre a intercomunicação da porosidade antes fechada por efeito da pressão interna dos gases, aparecendo defeitos na forma de borbulhas visíveis. Consequentemente, forma-se uma porosidade aberta muito grossa que eleva os valores de absorção de água. Ao ter uma via de escape dos gases formados, a peça se deforma somente pelo efeito da baixa viscosidade. Para retardar que a peça se comporte de acordo com a região IV deve-se utilizar um fundente em baixa proporção, ao mesmo tempo de baixo ponto de fusão e alta viscosidade (para evitar ao máximo a expansão dos gases caso estes existam).

A Fig. 3c apresenta o diagrama de gresificação que ocorre quando a formação de porosidade fechada acontece antes do fechamento da porosidade aberta. Este tipo de diagrama aparece quando são analisadas massas nas quais os feldspatos não são bem moídos e as inclusões amorfas ricas em voláteis ficam na parte interna dos grãos, sem poder escapar e dando lugar à dilatação da peça antes que se produza a fusão total dos fundentes. Isto também ocorre quando se utilizam fundentes muito enérgicos que geram fundidos de viscosidade muito baixa a uma temperatura muito mais baixa que quando ocorre a formação do fundido de alta viscosidade. Consequentemente, quando decide-se optar pela produção industrial de uma massa que tem este comportamento, a temperatura de queima deve estar compreendida na faixa $\Delta \mathrm{T}_{\mathrm{o}}$ da Fig. $3 \mathrm{c}$.

\section{APLICAÇÃODO MODELO}

Da aplicação das idéias e dos resultados do trabalho e modelos anteriores, surgem as seguintes sugestões:

i) As características essenciais de uma massa cerâmica para a produção industrial devem ser a gresificação à $\mathrm{T}_{\mathrm{o}}$ mínima possível, com a máxima faixa de temperaturas de estabilidade dimensional, sem a formação de porosidade fechada.

ii) A plasticidade da massa deve ser proporcionada por uma argila plástica de alta fundência, máximo conteúdo em caulinita e máxima concentração de partículas argilosas, que são suficientemente reativas para gerar um fundido de alta viscosidade que feche a porosidade aberta.

iii) Para proporcionar o máximo conteúdo em mulita, que é a fase responsável pelas propriedades de resistência mecânica deste tipo de cerâmica, deve-se utilizar o máximo possível de caulinita, não só com argila plástica, mas também com adições de caulim lavado de baixo conteúdo em grãos de quartzo.

iv) Redução da plasticidade excessiva do componente plástico dever ser alcançada com materiais não-plásticos [5] a base de quartzo, pois este é o responsável pela formação da porosidade interparticular. Além disso, a transição $\alpha-\beta$ do 
quartzo a $573{ }^{\circ} \mathrm{C}$ obriga a ciclos de queima com períodos de resfriamento lento na temperatura mencionada, diminuindo consideravelmente a capacidade de produção dos fornos industriais.

v) Fundentes com o mínimo possível tamanho de partícula deve ter a função não-plástica, além de substituir por um fundido à mínima temperatura possível com o máximo de viscosidade de fundido.

Com estas sugestões foi desenvolvida uma frita específica (M3) que foi adicionada à argila M1 com o caulim M2, resultando em massas com os diagramas de gresificação da Fig. 5. A mistura inicial de argila e caulim se comporta de acordo com o diagrama da Fig. 5a alcançando valores de absorção de água de 0,5\% a $1220^{\circ} \mathrm{C}$. Com a adição de $10 \%$ em peso da frita M3, estes valores são alcançados a $1200{ }^{\circ} \mathrm{C}$, mas com $20 \%$ em peso (ver Fig. $5 \mathrm{c}$ ) obtém-se cerâmicas do tipo grés porcelânico a temperaturas da ordem de $1150^{\circ} \mathrm{C}$, com uma faixa de estabilidade dimensional de cerca de $75^{\circ} \mathrm{C}$.

\section{CONCLUSÕES}

Com o desenvolvimento do trabalho, as seguintes conclusões podem ser descritas:

- O modelo proposto apresenta concordância com o comportamento térmico (curvas de gresificação) geral de massas cerâmicas de grés porcelânico;

- O desenvolvimento de uma nova formulação de massa baseada no modelo resultou em um material com uma ampla faixa de estabilidade dimensional (cerca de $100{ }^{\circ} \mathrm{C}$ ).

\section{REFERÊNCIAS}

[1] H. Liebermann, W. Schulle, "Basic properties of clay mineral raw materials and their influence on the microstructural formation during sintering", Ceram. Forum Int. 76, 10 (1999) 3134.

[2] K. N. Maiti, S. Kumar, "Efect of glass-ceramics and sillimanite sand additions on microstructure and properties of porcelain", Ceram. Int. 18, 6 (1992) 403-412.

[3] M. Subbanna, P. C. Kapur, Pradip, S. G. Malghan, "Population balance model for solid state sintering I. Pore shrinkage and densification", Ceram. Int. 27, 1 (2001) 57-62.

[4] M. Subbanna, P. C. Kapur, Pradip, "Computer-aided control of the evolution of microstructure during sintering", Mat. Chem. and Phys. 67, 1-3 (2001) 17-24.

[5] W. P. Tai, K. Kimura, K. Jinnai, “A new approach to anorthite porcelain bodies using nonplastic raw materials", J. Eur. Ceram. Soc. 22, 4 (2002) 463-470.

(Rec. 15/04/02, Ac. 09/08/02) 